\title{
PROFESSIONAL ISSUES FOR THE NIGERIAN VETERINARIAN IN THE TWENTY FIRST CENTURY
}

\author{
BABALOBI, 0.0 . \\ Department of Veterinary Public Health and Preventive Medicine, \\ University of Ibadan, Ibadan, Nigeria
}

\section{SUMMARY}

The imperative of enhanced professionalism of veterinary practice in Nigeria in a technologically advanced and sophisticated $21^{\text {st }}$ century is discussed. The concept of professionalism, the qualities of a professional, an overview of expectations from the Veterinary Council of Nigeria, Nigerian Veterinary Medical Association, Nigerian veterinary educational institutions, public sector veterinarians, private sector veterinarians and individuals in enhancing professionalism of veterinary practice in Nigeria are enumerated.

One of the challenges that will face the Nigerian veterinarian as we enter the twenty-first century is the response to the demands of an increasingly sophisticated Nigerian society. Definitely, the $21^{\text {st }}$ century will be characterized by increased application of science and technology and of higher taste, values and expectation from clients and consumers. How does the veterinarian respond appropriately to this? It is only by enhanced professionalism by veterinary practitioners that the profession can meet these imminent challenges. This paper highlights the areas where increased professionalism are called for, and the roles and functions of different veterinary groups in meeting these challenges.

KEY WORDS: Professionalism, Nigerian Veterinarian

The concept of Professionalism

A profession may be defined as an occupation requiring special knowledge and skill and its own peculiar ethics. Ethics, the science of healthy relationship (VCN 1985) is system (body) of moral principles, and rules of conduct that regulates the conduct of professionals in their relationship with their colleagues, patients, clients, legal authorities and the society at large. The presence of a code of ethics is a mark of professionalism.

\section{Qualities of a Profession}

According to Stoner and Wankel (1988), professionals must be governed by a strict code of ethics to protect the client because of the professional's expert knowledge in a specific area, which makes the clients to be dependent upon the professional, as a result of which the client is in a vulnerable position. Qualities of a professional are
(a) Possession of special knowledge and skill
(b) A strict code of ethics
(c) Personal dedication and commitment
(d) Achievement of professional status through performance and not through favoritism or other factors irrelevant to the work at hand, and
(e) Informed judgment and decisions based on general professional principles.

\footnotetext{
Vlissingen (2001) has described veterinarians as professionals who must make ad hoc decisions that influence the fate of animals and affect the lives of the
} 
people who own or look after them. They also have to address issues of public interest, such as public health. The central role they play in decision-making implies considerable collective and individual responsibility. In the process of making decisions there are invariably different interests at stake, all of which must be considered: there are those of

The animal,

The owner,

A third party (which may be society as a whole) and

The veterinarian.

Vlssigen, with a view to developing a model for decision-making and identifying the relevant professional responsibilities, has summarized the interests of all parties concerned as follows:

* Animals' interests: the availability of therapy, the chance of therapy being successful, the quality of life after recovery from therapy and the amount and duration of pain and distress during the period of treatment and healing.

* Owners' interest: consideration for the health and well being of the animal, the emotional bond with the animal, the costs of treatment monetary and labour, the chances of successful treatment and the suitability of the animal for its intended use after healing.

Veterinarians' interests: consideration for the health and well being of the animal, his relationship with the client and the professional challenge and commercial interest the case offers, public health consideration. Interest of the population to which the animal belongs: the absence of inheritable problems that cause serious defects, absence of animal diseases that might become epidemic and jeopardize the continuity of the population, preventive medicine measures.

* Public health interests:

o Risks to workers or consumers

Availability of nutritious and safe foodstuffs at a reasonable cost.

* Economic interests: availability of animal products at a reasonable cost, continuity of business for primary producers and related business.

\section{An Overview of the Veterinary Profession in Nigeria}

The earliest reference to the veterinary profession in Nigeria is that in 1904 of a certain veterinary Capital Carr of the Royal Army Veterinary Corps to Nigeria. With the establishment of the Veterinary department in 1914, two veterinary officers, G.E. Owen and F.R. Brandt were recruited. In 1954 the first Nigerian veterinary doctor, Dr. Bukar Shuiab graduated from the University of Liverpool in the United Kingdom. In June 1967, the first veterinarian wholly trained in Nigeria, Dr. Basil Ikede graduated, jointly trained by the two veterinary faculties in the University of Ibadan and Ahmadu Bello University, Zaria (VCN 1985).

The Nigerian Veterinary Medical Association (NVMA) is the professional association of veterinarians in Nigeria. It became active in 1966/67, although it probably had a precursor in the Nigerian Veterinary Association (NVA) referred to by Mr. Henderson in 1945 (VCN 1985). The body with statutory responsibility for regulating the Veterinary profession is the Veterinary Council of Nigeria (VCN). It came into existence by virtue of Ordinance No 30 of 1952, and its composition and responsibilities are stated in the ordinance No 30 of 1952 as amended by Federal 
Legal Notice (FLN) No 131 of 1954, FLN No 37 of 1958 and Veterinary Surgeons Decree No 37 of 1969. Its functions are related in the main to the general duty of:

a. Determining what standard of knowledge and skills are to be attained by persons seeking to be registered as veterinary surgeons in Nigeria, and of raising these standards from time to time as circumstances may permit.

b. Establishment, maintenance and publication of a register of person registered as veterinary surgeons in Nigeria.

It can thus be stated that the following bodies and individuals are responsible for the enhancement of professionalism of veterinary practice in Nigeria:

a. The Veterinary Council of Nigeria (VCN)

b. The Faculties of Veterinary

Medicine in Nigeria.

c. The Nigeria Veterinary Medical Association (NVMA)

d. The Individual Veterinarians either as:

(i) Policy makers in government

(ii) Government veterinary practitioners

(iii) Private veterinary practitioners

\section{The State of the Veterinary Profession in Nigeria}

According to the Veterinary Register (2000), there are more than three thousand four hundred (3400) registered veterinary surgeons in Nigeria. The veterinarians are distributed in the government (public) sector in the academic (Universities and other higher institutions) and in private sector (Veterinary practice, private firms, drug firms, feed industry etc). As of 1985 , over 90 percent of registered veterinarians were in the public sector (VCN 1985) but over the last two decade, the greater proportion of registered veterinarians has been employed in the private sector.

As the veterinary profession in Nigeria becomes increasingly privatized, the imperative of professionalism becomes paramount. This is because private veterinary practice will become the window through which the veterinary profession will be judged, as the client makes greater demands not only to justify payments for services provided, but also on the quality and the modernization of the services provided. There is the need to adjust veterinary education towards societal expectations, from the veterinary professions. Likewise, the VCN will need to raise the standard required for registration and practice while veterinarians in government and policy making will also need to update themselves with the skills and knowledge necessary for the challenges ahead.

\section{Expectations}

For the veterinary profession in Nigeria to meet the imperative of professionalism for the $21^{\mathrm{st}}$ century, the following roles are required of the relevant statutory bodies, groups and individuals in the veterinary profession.

\section{The role of the Veterinary Council of Nigeria (VCN)}

In its statutory function of determining and raising from time to time the standards of knowledge and skills to be attained by registered veterinarians in Nigeria, the VCN is expected to:

i. Ensure that the curricula of veterinary facilities in Nigeria are expanded to highlight the role of science and technology (especially computer technology) in the effective delivery of modern veterinary medicine. 
ii. Ensure that the curricula emphasize the epizootiological perspective to preventive veterinary medical practice, which is as ever more reliable, cost effective and more beneficial to the client, patient and society, than curative medicine.

iii. Make policies that will adopt and promote the concept of Community Based Participatory Epizootiology involving local livestock owners, and the training and control of privatized Community Animal Health Workers for sustainable livestock development and disease control measures. These concepts have produced successful sustainable results in East and Central Africa.

iv. Implement fully the Post-Graduate College of Veterinary Surgeons to provide opportunities for veterinarians to develop much needed expertise in specific areas of the veterinary curricula as Members and Fellows of the Nigerian College of Veterinary Surgeons.

v. Demand and get and active voice in the certification of veterinary assistants - the veterinary OND and HND holders. At presents, it is the National Board for Technical Education (NBTE) that is solely responsible for this certification, making the veterinary profession as about the only one in Nigeria that has no say whatever in the regulation of its support personnel.

vi. Organize and strictly enforce regular Continuing Education Programme (CEP) for practicing veterinarians, as prerequisite for renewal of their registration. Such CEP will provide for crossfertilization of ideas between academics and public sector veterinarians among others.

vii. Monitor private practice of individual veterinarians, and enforce professional discipline by appropriate sanctioning of defaulting veterinarians.

viii. Regularize identification and successful prosecution of quacks and impersonates, to serve as deterrent to others and uphold professionalism.

ix. In conjunction with veterinarians in policy making positions in government, review existing veterinary related laws detrimental to the veterinary professions either in content, or by the meager punishment provided for the breaking of such laws. Examples include the Pharmacy Law of 1946, Oyo State Meat Edict of 1978 and similar laws related to public health and other multidisciplinary collaborations.

\section{The role of Veterinary Education Institutions}

The Faculties of Veterinary Medicine in Nigeria are expected to respond to the imperative professionalism in the following ways:

i. Expand the curricula to introduce students to such subjects as computer appreciation and application to the provision of modern veterinary services delivery, epizootiological perspectives to the delivery of preventive veterinary medicine and veterinary ethics and jurisprudence. 
ii. Adopt and promote in veterinary curricular, the concept of Community Based Participatory Epizootiology and the training of Community based Animal Health Workers, involving local livestock owners for sustainable livestock development and disease control measures respectively. This concept has produced successful results in East and Central Africa.

iii. The use of modern diagnostic aids in the teaching and instruction of veterinary students.

iv. Improvement in the practical teaching content of the veterinary education programme either by ensuring that the present practice of industrial attachment during long vacations are exploited to maximum practical advantage, or by ensuring that the last one year of veterinary programme is entirely devoted to clinical practice internship as in human medicine.

$v$ Keeping in touch with current veterinary developments in veterinary curricula in advanced countries and inculcating them into the veterinary curriculum.

The role or Veterinarians in public sector

Public sector veterinarians (policy makers and practitioners) are expected to respond to the imperative of professionalism in the $21^{\text {st }}$ century in the following ways.

i. Policy makers are expected to make realistic and sustainable input to decisions based on expert knowledge. This calls for policy makers to update their current knowledge by attending Continuous Education Programme, relevant workshops, conferences and symposia; as well as acquisition of higher postgraduate degree and Postgraduate Membership or Fellowship diplomas, rather than relying on outdated experience.

ii. It is the responsibility of and expectation from public sector veterinarians to ensure that the profession is not disadvantaged in the implementation of government policies. They are to defend the interest of the profession and ensure that other professions or vocations especially in the medical and agricultural fields do not usurp the profession's privileges and responsibilities. The profession must also fight off challenges from other groups portraying themselves as protectors of animals. As Dr. Howell 2002 2003 President of the American Veterinary Medicial Association (AVMA) stated, veterinarians are "the ultimate animal welfare people, and no other group has done as much to relieve animal suffering and pain or increase (animal) wellbeing as veterinarians".

iii. They are also to monitor developments in the sister medical profession and ensure that privileges extended to the profession apply to the veterinary profession, to ensure parity.

iv. Public sector veterinary practitioners must not only be 


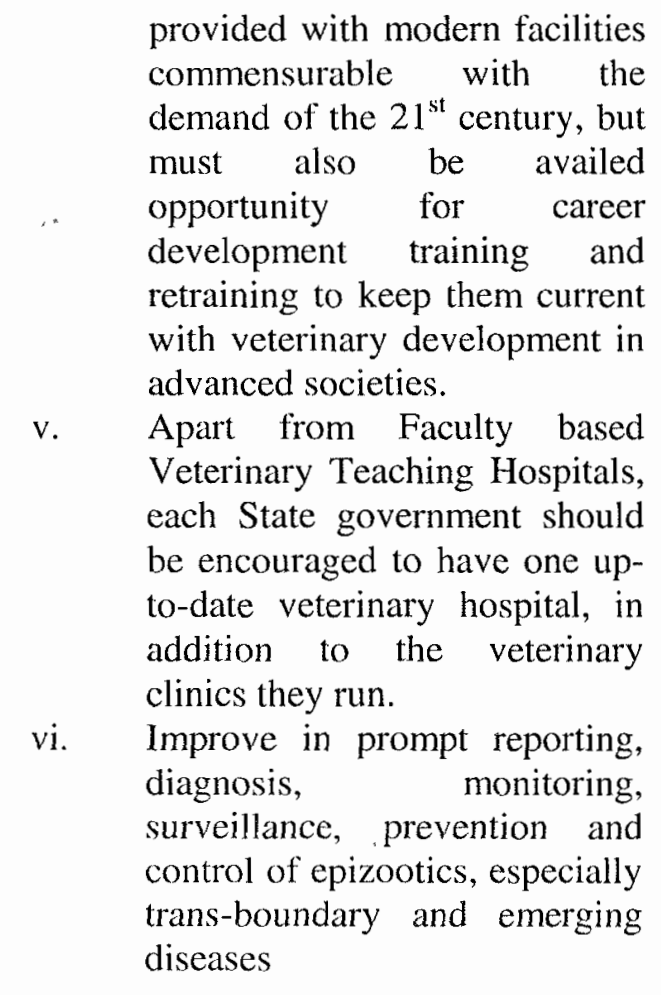

\section{The role of Nigerian Veterinary Medical Association (NVMA)}

The role of the NVMA should be in the areas of:

i. Protection of the interest of the profession and keeping it at par with identical profession.

ii. Public relations activities to promote the profession's image

iii. Servicing as vanguard to promote professionalism and ethical conduct in private and public sectors.

iv. Encouragement of formation of specialized bodies and groups within the NVMA for more effective.. professionalism. Examples of such groups could include association of private practitioners, large animal practitioners, small animal practitioners, public health sector practitioners, etc.
The role of Private Sector Veterinarians

i. More than any other group of veterinarian, the private veterinary practitioners must imbibe and exhibit all the qualities of professionalism as they come into daily contact with their clientele. These are related to application of veterinary knowledge and skill, dedication and commitment to duty.

ii. Private sector veterinarians should apply the epizootiological perspective to diagnosis as disease problem has not only biomedical component but also ecological, socio-economic and biostatical components.

iii. Professional practice must be based on principles of preventive veterinary medicine in realization of the fact that prevention is not only cheaper, better and more effective than cure, but will enhance the appreciation of the veterinarian as a professional.

iv. It is the responsibility of the private veterinary practitioner and other Nigerian veterinarians to keep up to date with current veterinary developments in advanced countries, by attending training and retraining courses, conferences, seminars and symposia, and subscribing to modern veterinary journals and publications.

v. Private veterinarians are expected to learn and imbibe management skill and abilities for sustained practice. Kept in tune with modern management principles. 
vi. It will be expected that specialized private practices and large private veterinary hospitals will evolve to provide specialized services to clients and patients. Such specialization could be in the areas of surgery, canine practice, large animal practice, laboratory animal practice, poultry and livestock feed production. Concomitantly, it will be expected that operators and practitioners of such specialized practices will possess the cognate experience and post-graduate qualifications required for such specialization.

vii. Accommodate the role of Community- based Animal Health Workers in rural areas which have a greater population of animals and where private veterinarians will not live or practice due to lack of financial and socioeconomic facilities.

viii. More than other issues, private veterinary practice must be in strict compliance with veterinary ethics and code of conduct as highlighted earlier. It is only by so doing that the professional will win the respect of his colleagues, client and society, and justify the privileges of the profession.

\section{CONCLUSION}

The individual veterinarian has to imbibe and practice the principles of equity, social responsibility, commitment, integrity, dedication, natural justice, personal development (mental, physical, social, spiritual, financial, professional etc), professional dignity, professional conduct and comportment. This will enhance the professional status of the Nigerian veterinarian and his relevance to the Nigerian society now and into the $21^{\text {st }}$ century.

\section{REFERENCES}

HOWELL A. (2002) (Source: http://www.avma.org/onlnews/jav $\mathrm{ma} / \mathrm{sep} 02 / 020901 \mathrm{c}$.asp).

LAWS OF THE FEDERAL REPUBLIC OF NIGERIA (1948). Pharmacy Act No. 169. Nigeria

OYO STATE MEAT EDICT (1978). Oyo State Nigeria.

STONER J.M.F. and WANKEL C. (1988): Management. Prentice Hill of Indian New Delhi.

THE VETERINARY REGISTER (2000). Veterinary Council of Nigeria. 193pp.

VETERINARY COUNCIL OF NIGERIA, VCN (1985). Veterinary Profession and Ethics in Nigeria. 36pp.

VLISSINGEN M.F. (2001) Professional Ethic In Veterinary Science Considering The Consequences As A Tool For Problem Solving. Veterinary Sciences Tomorrow. Issue 1, January 2001. (Source: http://www.vetscite.org/issue1/poli cies). 